\title{
Article
}

\section{Children Changing Spaces, Changing Schools}

Crook, Deborah

Available at http://clok.uclan.ac.uk/35854/

Crook, Deborah ORCID: 0000-0003-1852-1130 (2021) Children Changing Spaces, Changing Schools. Children \& Society, 35 (3). pp. 445-460. ISSN 09510605

It is advisable to refer to the publisher's version if you intend to cite from the work. http://dx.doi.org/10.1111/chso.12429

For more information about UCLan's research in this area go to http://www.uclan.ac.uk/researchgroups/ and search for < name of research Group>.

For information about Research generally at UCLan please go to http://www.uclan.ac.uk/research/

All outputs in CLoK are protected by Intellectual Property Rights law, including Copyright law. Copyright, IPR and Moral Rights for the works on this site are retained by the individual authors and/or other copyright owners. Terms and conditions for use of this material are defined in the policies page.

\section{CLoK}

Central Lancashire online Knowledge www.clok.uclan.ac.uk

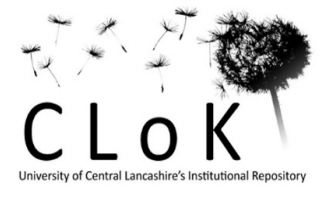




\title{
Children Changing Spaces, Changing Schools
}

\begin{abstract}
Children's participation remains controversial in United Kingdom schools where children and their communities rarely have opportunity to change what happens. This paper considers an original approach that developed cooperative intergenerational inquiry with a class of 10-11year-olds in the north of England as part of complexity-informed participatory action research to consider children's participation in schools. Children and adults considered together, what schools are for, at the same time enabling children to shape spaces for participation in lesson time. The importance of recognising these spaces as dynamic intra-subjective meeting points and of intergenerational relationships for change in schools is revealed.
\end{abstract}

\section{KEYWORDS}

Children's participation; children's rights; intergenerational; cooperative inquiry; schools

\section{INTRODUCTION}

Children and their communities rarely have opportunity to direct or change what happens in school classrooms, especially in the UK where participation rights remain controversial (Fielding and Moss, 2011; Harris, 2005; Horgan et al., 2017). Education research tends to consider the child as learner in preparation for adulthood, and the teacher as instrumental to this process, but seldom their relationships, or the effects of generational order. Work in the field of childhood studies contests adult-centric developmentalism but has had limited impact on related disciplines (Punch, 2019) and even less on education policy. There is a gap between theory and practice in schools, especially in nations where reforms have narrowed children's educational experience and outcomes. This paper presents an example of how that gap might begin to be addressed and in doing so acknowledges some of the different ways everyday participation is envisaged in pockets across the globe.

The United Nations Convention on the Rights of the Child (United Nations, 1989), UNCRC hereafter, asserts that children have participation rights, including those necessary to express a view in all matters that affect their lives. Although most UK schools have some form of student voice or council, evidence is scarce that children have any meaningful participation in deciding what happens in their classrooms, the curriculum, or what and how they learn. Participation itself can have many meanings (Anderson et al., 2019); in education it is a complex issue where dualisms between individualistic and collective standpoints abound (Theobald, 2019). If we understand participation as children taking an active part in decisions that influence their lives and issues that concern them, making things happen by developing and expressing their views, and joining with others to make the world a better place, such activities if they happen at all in schools are generally side-lined as extra-curricular; yet surely these are necessary for building cooperation and more equitable societies? The study 
presented here was designed to explore how such participation could be developed in primary school classrooms, despite strong political forces that can hinder such ways of being.

In addition to participation rights - to a view, access to information, freedom of expression and association - the UNCRC declares that every child should have access to free primary education that respects their dignity, enables them to reach their potential (Article 28), fully develops every child's personalities, talents, mental and physical abilities, and encourages respect for others' human rights, their own and other cultures. Children should learn to live peacefully and protect the planet on which we all rely (Article 29). Thus, education is about both socialisation and individual growth, enabling children to flourish as active members of communities in the now, as well as in the future, and reinforcing citizenship (Harris, 2005; Johnson and Johnson, 2016).

Complex connections between education and democracy, about which Dewey wrote a hundred years ago, tend to be obscured by the 'neoliberal' drive to standardise education systems - indeed to standardise children, to maintain a globally dominant economic system (Bath et al., 2020; Fielding and Moss, 2011; Harris, 2005; Sahlberg, 2011). Global education reform has driven competition and personalisation in schools, with children expected to attain ever higher targets, to satisfy wealth generation structures, reducing opportunities for broader learning and maintaining inequalities (Fielding and Moss, 2011; Sahlberg, 2011). Participation initiatives may prioritise individual autonomy, encouraging children to selfregulate to current norms, shifting educational processes away from the collective (Raby, 2014). Democratic processes in turn, may further collective needs at the expense of individual flourishing, emphasising performativity to meet the adult agendas dominating school decisions and practice; even when children's views are sought, it is to inform such agendas (Robinson, 2014). Around the world, reflection on the purpose of primary education, by children and their communities, is rarely encouraged by political systems that commit to its provision predominantly as a production process (Krstić, 2016).

Teachers who want to encourage participatory spaces in schools, have to navigate these complexities: differing theories about agency, social order, what participation means and how it is enacted in the $21^{\text {st }}$ Century. They face challenging decisions as they manage curriculum, pedagogic possibilities and children's interactions, interconnected with strong political forces (Theobald and Kultti 2012). Although there is criticism that the UNCRC itself colonises neoliberal ideas (Wyness, 2013), it is argued here that it is still a useful means of resistance because it recognises children and adults as important actors and shapers of societies and their systems, drawing attention to intergenerational relationships.

This study addressed the question of whether it is possible to facilitate children's participation in a school, in adverse political contexts, through a novel approach to participatory action research (PAR) (Hall, 2005; Kindon, Pain and Kesby, 2007), whilst simultaneously asking children and adults to work together on a question that would necessitate their reflection on participation and education. This article considers the responses of one primary school class of 10 and 11-year-olds in northern England, their teacher, and members of their community as they worked together with the researcher (Author) to consider the question 'What are schools for?' It discusses how by using intergenerational cooperative inquiry as a process of complexity-informed PAR (Crook, forthcoming), they were able to work together to co-construct deeper understanding. Student inquiry promotes 
independent learning, enabling children to explore and share their views about issues that concern them (Kellett, 2005) but in itself seldom leads to change in the status of children or in education systems. Cooperative inquiry involves actors within systems working together and has the potential to awaken a sense of injustice, encourage children to recognise others and understand democratic values, much like its counterpart in education - cooperative learning (Johnson and Johnson, 2016) - a technique used to varying degrees across the globe.

The resulting rich datasets are too large to be fully reflected here. However, this paper shows the potential of research that starts out by thinking differently about children and schools. It considers what might emerge if researchers and educationalists question schooling agendas (Harris, 2005; Krstić, 2016), by embracing approaches that enable school communities to work together to understand how intergenerational relationships affect children's participation rights. Fuller engagement with evidence of children's agency from childhood studies to address inequities is suggested (Bessell, 2017; Horgan et al., 2017; Punch, 2019; Thomas, 2012).

Data and analysis are presented revealing perspectives about participation, along with a summary of educational outcomes that these participants considered important. The results indicated that UK policy, and dominant global forces affecting this and the ways through which childhood is constituted, are at odds with what this community hoped to achieve through schooling. As the school students demonstrated, children can reposition themselves as capable, cooperative, agents of change, when barriers produced by adult agendas are reduced. In working with adults to change educational spaces, through intergenerational cooperative inquiry, these spaces are revealed as dynamic meeting points, where relationships can grow and potentially enable novelty and change.

\section{BACKGROUND}

UK children spend a great deal of their lives in schools learning much through everyday processes - positive or negative - including their participation (Horgan et al., 2017). Schools inculcate values in children, whether intentionally through curriculum and pedagogy, or implicitly through the ways in which various roles are constructed and interactions are managed (Johnson and Johnson, 2016; Krstić, 2016). Education is always political because knowledge both empowers and disempowers (Biesta and Osberg, 2010), suggesting schools have a responsibility to ensure children and adults understand how knowledge is produced, its provisional nature, and how values evolve (Cilliers, 2005).

How children are encouraged to participate and construct or share knowledge is limited through standardisation (Raby, 2014). One cost of this is that those who do not comply are defined as deviant or failures, excluded and made responsible for personal deficits, rather than responding to injustice (Smyth, 2014). Another is that for all children it promotes transmittive approaches to teaching and knowledge accumulation (Bath et al., 2020; Freire, 1970; Kirschner et al., 2006), leaving few opportunities to engage with the subjective through rich relationships and complex thinking needed to acknowledge the limits of knowledge and strive for it (Cilliers, 2005). Children and teachers are positioned in ways that privilege school agendas over individual learning, and teachers' roles over children's interests, hopes, and intentions (Theobald and Kultti, 2012). 
Such narrowing of education has been criticised (Bath et al., 2020; Brighouse, 2007; Fielding and Moss, 2011; Freire, 1970; Harris, 2005; Osberg and Biesta, 2008; Sahlberg, 2011). In England, the Cambridge Primary Review (Alexander, 2010) provides a vision of what primary education system should be, acknowledging children as integral, emphasising voice, community engagement, sustainability, and a broad, balanced, creative curriculum. Education for the Good Society: The values and principles of a new comprehensive vision (Lawson and Spours, 2011), supported by the National Union of Teacher, suggests democratization of schools. Yet, failure of the UK political establishment to respond is evident through privatisation of schools and retrenchment of teacher education, conducted mainly in schools, and lacking strong pedagogical foundations (Bath et al., 2020).

Education systems that have to some extent resisted global reform, include Finland with its rights-based culture, which unlike the UK operates through a systemic approach to equity in education, is free, and enables teachers to work together to devise curricula (Sahlberg, 2011). Research in Australia and Scotland, suggests that a culture of children's participation, based on relationships of recognition, can have a positive effect on both achievement and wellbeing (Graham et al., 2018; Mannion et al., 2015; Thomas et al., 2016). A Welsh Government report (Estyn, 2019), suggests that relationships between teachers and children, and children and their peers, are critical factors for children's health and well-being and that whole school approaches with opportunities for children to express their views are needed. Increasing numbers of UK schools are working towards UNICEF's Rights Respecting School Award that aims to embed children's rights in everyday life, but uptake has been slow (Robinson, 2014). These examples show how innovation that critiques the status quo, putting theory into practice is possible; further research is needed to understand more about how and when.

A focus on intergenerational relationships is one useful strand of investigation. Childhood studies has indicated the importance of children's agency and capacities for participation but less so relationships necessary for their exercise (Bessell, 2017; Horgan et al., 2017; Punch, 2019). Schooling and neo-liberal forces interfere with these (Raby, 2014) negating the importance of relationships in the formation of dynamic educational spaces, rather than those constricted for transmittive processes that allow teachers to cultivate progress (Kirschner $e t$ al., 2006; Krstić, 2016). Yet rich relationships develop through recognition of each other's needs, and actions that demonstrate this. Thomas (2012), following Honneth (1995), characterises recognition in terms of love, rights and solidarity, which he argues are necessary underpinnings for participation. Without explicit attention to more equitable relationships through recognition in schools, children may be prevented from exercising their rights.

Cooperative inquiry is also a potentially fertile area of research. Inquiry promotes participatory practice by establishing learning as a dynamic, interactional process of coconstruction (Guldberg et al, 2017). This depends on experience and understanding so far constructed - what is known but also what is not yet known or possibility (Rasmussen, 2010). Unlike outcome driven group-work, cooperative learning promotes trust, cooperation, constructive conflict resolution, social justice and freedom from oppression (Johnson and Johnson, 2016). Bringing these together requires a change in agenda and positioning of children and adults. Intergenerational cooperative inquiry might establish this through appreciation of how intergenerational processes are experienced and communities' potential 
to broaden contexts of learning (Mannion, 2016). Through this the relevance of children's participation through cooperative inquiry becomes clear; instead of elevating the status or power of some children, it aims for more equitable interactions across the school and community (Fielding and Moss, 2011).

To understand such practice in schools within an adverse political context, this study therefore utilised PAR to experiment in democratisation, creating opportunities for intergenerational cooperative inquiry, enabling children to identify common goals, make decisions together, work with adults to construct relevant processes, and potentially for adults to re-imagine their educational relationships with children. This enabled study of how spaces changed. By situating these processes in time and space, it was possible to explore how intergenerational relationships affects the ways through which children and adults envisage participation and can work together for change.

\section{METHODOLOGY}

The methods used were informed by applying complexity theory to PAR, further described in (Crook, forthcoming). Schools are dynamic, constantly adapting to influences within and outside the system, through the multiple interactions and interconnectedness of people involved (Haggis, 2008). PAR, understood as an ongoing process of action and reflection, combining research, action and education to overcome the problems faced by social groups (Kindon et al., 2007; Hall, 2005), enables actors - in this case children, teachers and members of the wider community - to appreciate and understand their situation (Freire, 1970). Exploring the complexities of participation in primary education, required approaches that simultaneously enabled children and adults to reflect on and experience participation.

\section{Research Design}

The school, an average sized Catholic primary in a small town in northern England, draws children from broad socio-economic backgrounds, including areas of high disadvantage. The ethos and characteristics of the school were potentially important, the children and head teacher referring to their school 'family.' Although the UNCRC was not embedded in local or national policy, and the teachers, children and community involved did not refer to this, it does not mean that they did not consider children's rights. Further research across different schools is needed to address how school characteristics enable or create barriers to participation and to consider the extent to which learning from this example is transferrable to other contexts. Recruitment of a whole existing class of children was important to ensure processes were inclusive and responsive; variation and difference being considered as positive, normal system components, essential to change. Few school classes fully represent socio-economic diversity at the macro level, and sampling does not enable study of existing relationships or contexts likely to affect participation (Woodhead and Faulkner, 2008); thus, data about gender, disadvantage, disability or special educational needs were not recorded about each child unless shared during interactions, in which case they were noted in a reflective journal. 
The class of 24 children aged 10-11 considered the question: 'What are schools for?' Their parents or other family were invited to complete a questionnaire and volunteer to take part in intergenerational work with the children. Eleven adult volunteers - including parents, grandparents, a sibling and a school governor) worked with the children on two occasions. As a former schoolteacher, I had experienced positive 'bring your parents to school' days which inspired the intergenerational approach. The volunteers and children's parents were asked to complete a questionnaire about their perspectives on participation and education; 28 were completed which included $85 \%$ of the parents. The 24 children also completed a 'childfriendly' version.

I planned PAR workshops for one afternoon per week, for six weeks, during the period following statutory state tests, before the children transferred to secondary school. The teacher wanted the children to develop useful study and social skills that she hoped would prepare them for this transition. Activities were co-facilitated with the teacher to enable children to conduct inquiry, explore their ideas about participation and their education through the 'words, ideas, conditions, and habits central to their experience' (Freire, 1970:31) and increasingly in planning and deciding how to approach the research question. Focus was on the space (physical and intersubjective) through which they conducted their inquiry and co-produced knowledge with the volunteers. The approach was inspired by other student inquiry approaches especially Kellett (2005); however, the aim was to examine the process of participation and views about participation and education co-constructed through this.

\section{Ethics}

I visited the class to discuss the research and how we might work together. [University] and BERA ethics guidelines were followed and procedures approved by the University ethics committee. With the headteacher's permission, the school sent home information sheets to parents/carers, including details of how they could volunteer and how they or their child could withdraw from the research. As the research activities were designed to be educational, I chose this 'opt out' approach to ensure that children who wanted to take part in their class's activities could not be unfairly excluded through lack of completed paperwork from parents; such exclusion from peer groups is not considered to be in a child's best interests.

Although, as Alderson and Morrow (2011) point out, it can be a mistake to argue that research is beneficial to children when it is a process of collecting data, producing and sharing results, not directly benefitting participants, children's inquiry does offer educational benefits and the process was designed to enable children to exercise their rights.

Nevertheless, the research was distinct classroom activity, thus it was important for both children and parents to have the option to withdraw. Each week, we discussed what data would be collected and why, so that children were 'truly informed' (Gallagher et al., 2010) and could decide at whether they would allow me to record data or include what they produced in their lessons as part of the research.

\section{Data Collection Methods}

Together with questionnaires which asked about perspectives on children's participation and education, the workshop activities explored: what participation means for children; how school experiences vary or are similar; how sharing ideas potentially helps groups to construct more meaningful views about education and participation; and developing ideas 
about what schools should ideally provide. The children decided to research adults' school experiences using semi-structured interviews, preparing and conducting these in small groups of two or three per one or two adult volunteers, and learning how to use recording and editing software on the school's digital notepads. They analysed the interviews to identify similarities and differences between their own and the adults' experiences, before developing presentations (posters, PowerPoint presentations or podcasts) to share their findings. The adults were then invited back to school for a mini-conference. The children's presentations generated discussion in seven intergenerational focus groups who then created large drawings showing what they hoped schools would 'gift' to students in terms of developing them as young people, and what schools should ideally be for.

Data generated included questionnaire responses, the children's interviews with adult volunteers, their presentations written comments and evaluations by the researcher and participants, photos of the groups on task, video and audio recordings of the mini-conference and drawings created during their intergenerational discussions (images were digitally photographed). I kept a reflective journal recording observations, discussions with the teacher and children, our evaluation of and plans for each week's activities.

\section{Data Analysis}

Two phases of thematic analysis were applied to the data (using MAX-QDA to assist). The first phase used free-coding, establishing questions to aid analysis of the video and sound recordings and co-constructed drawings. Such analysis is challenging because data is open to multiple interpretations. However, the mixed data types enabled contexts to also be considered, including for example, whether produced as individual viewpoints about past experience, as responses to the participation or generated through social and intergenerational interaction. Three other researchers took part in panel analysis to ensure as many elements as possible were considered consistently. The second phase re-grouped the analysis into themes or 'pattern codes' (Miles et al., 2013) to develop a cognitive map of the interactions and events in each developing space. Two resulting datasets represented views and attitudes that describe: children's participation - how children are involved, how and why, or whether they should be; and education - what this is perceived to be, what the community would like it to be, and what was important to participants.

This paper is concerned with how spaces changed and subtle differences between emphasis of themes across the study and especially when co-constructed through the intergenerational mini-conference. By considering data subsets that referred to past, present and future views about education and participation, temporal shifts in emphasis could be observed. For example, questionnaire responses were mainly about past experience, with views about current education and participation reflecting these. Data generated through the workshops was sometimes based on more recent experience, such as what children had learned to expect from school. The intergenerational inquiry enabled them to consider other viewpoints and eventually work together with the adults to co-construct views about what schools should be for - their future viewpoint. Differences in emphasis were important for understanding the impact and potential of spaces created - the ways in which views were constructed in these spaces, their interconnectedness and complexity of educational systems (Haggis, 2008). 
Examples in the next two results sections illustrate how perceptions changed as the children and adults experienced participation through the intergenerational cooperative inquiry process. A summary of the themes across the two datasets is provided in order to demonstrate how they interconnect.

\section{HOW CHILDREN SHAPED SPACES}

\section{The starting point}

Questionnaire responses showed little acknowledgement that children have participation rights. Adults' responses about participation were mixed, some suggesting a role for children: 'Children's wisdom can be very profound.' Others about aged based capacities and adults being better placed to make decisions:

'Not as much as their parents. Children don't always have the confidence to speak out or they can't easily communicate their feelings'

'They are not experienced enough to make decisions and should not be placed under that pressure.'

Although one parent asserted that 'the basic principle of what schools are for is already widely established and understood,' there was considerable variation and lack of congruence between ideas about school purpose and what happens in them. Adults and children commonly described tense relationships but adults framed schooling as preparation for the future, whilst children were more likely to critique the present situation and adults' behaviours: 'people bullying others,' 'when teachers shout,' and 'rude dinner ladies.'

\section{The workshops and changing space}

During the first workshop, children were asked about their participation at school. Two thirds believed that they should have a say in what happens. A third did not because of concerns about behaviour, fairness and inequity, for example: 'Because people could argue or not like the plans.'

Another activity 'Me and my community' encouraged the children to draw groups they belonged to, arranging these to show where they believed they enjoyed most participation through their actions and influence, or shared decision-making. All placed family and close friends at the centre, explaining how they could say what they think and that what they said was listened and acted upon, resonating with Lundy's (2007) 'safe space' and 'audience.' School for most was absent or on the periphery, apparently reflecting children's doubts that their participation could happen in school.

During activities to facilitate the children's own inquiry, at first their input and planning was more limited than I hoped because they were so accustomed to receiving instructions before engaging in tasks. They appeared uncomfortable with requests to discuss ideas with the person next to them or to physically get up and move to talk to someone else. It was only late in the second session where questions such as 'Can we...?' started to emerge and well in to the fourth session where children began to take initiative. 
A milestone in cooperation occurred when children wrote semi-structured interview schedules for interviews with the volunteers, one group suggesting that each group photocopy and share their questions with the others, so they all had a range of questions. Concurrently, children began to use the word 'we' when referring to their actions in their groups. With this came a change in use of the physical space, as children used the photocopier independently; as their confidence in taking decisions grew, and on realising they needed physical distance to conduct interviews satisfactorily, groups decided to work in other areas of the school. During the final session, they moved freely between the classroom and school hall to plan and set up for the mini-conference. The teacher refrained from intervening, showing increasing trust and confidence in the children's capacity to self-govern actions.

\section{THE EMERGENT SPACE AND CO-CONSTRUCTED VIEWS}

Prior concerns about anti-social behaviour appeared to be alleviated through the experience of intergenerational cooperative inquiry. Occasional instances occurred but did not escalate as children increasingly worked together and regulated these themselves. For example, two boys repeatedly shouted 'YOLO' (you only live once) during the mini-conference; this irritated some of the other children who eventually asked them politely to stop, the boys then moderating their actions and adding the word to their group's drawings. This shift away from concerns about interactions was echoed through participants views about participation (Crook, forthcoming).

Themes drawn from across the data about participation and about the purpose of education are summarised below. I then describe how emphasis within the participation dataset shifted through the PAR process and how this relates to the themes about education.

\section{Themes about children's participation}

There were six themes expressed through both positive and negative examples:

- Understanding included: different points of view and perspectives, sharing knowledge, and experience; for example: 'Their input may give insight to the decision makers' and 'Because kids know what they need to learn and what they don't.'

- Interactions included: being with, socialising, relationships, behaviours, sharing, and learning from experience; for example: 'Because they can make school a lot more better and can help people with situations'

- Well-being included: enjoyment, support, balance, help, and well-rounded; for example: 'Yes a happy child will learn a lot more.'

- Equity included: justice, fairness, meeting all children's needs, helping and bridging gaps; for example: 'Because school is not fair and there should be a bit more justice in school!'

- Involvement included: to share, give, speak, listen, have a say, bridge, question, make decisions, practical skills needed to take part, citizenship, as well as negative discrimination and exclusion; for example, 'They are listened to and treated as members of the school community.'

- Ownership included: reflecting, considering, changing views, possibilities, and future; for example, 'Because it is their education.'

\section{Themes about education through schools}


There were seven themes:

- Future aspirations included: what it means to be successful, talent, all round education, knowledge for the future, university, becomings, jobs and economy - 'you only live once.'

- Citizenship included: being respectful (especially when about behaviour), respecting others, taught respect, positions of responsibility, assemblies, discipline, boundaries, jobs at school, acceptable behaviour and 'antidisestablishmentarianism.'

- Life skills included: literacy skills, numeric skills, wisdom, individual, prepared, disciplined, improvisation, taking care of yourself, determined, different experiences, being more independent, fast brain, thinking, and confidence.

- Knowledge included: subjects, school trips, subject skills such as musical, homework, exams, learning new things, maths, science and languages - 'know/learn a lot'

- Social skills included: social life, manners, patience, communication, team sport, playing, listening skills and being polite, unselfish and helpful.

- Relationships included recognition and well-being through love, friendships, being valued, loyal, nurtured, looked after, cared for, facilities (space to play), doing your best.

- Values included: beliefs, being kind, tolerance, equity, and respect for difference 'love one another.'

\section{Shifting Perspectives}

Shifts in how themes were emphasised were apparent depending on the contexts in which data was generated. These appeared to be the result of the changing space, the dynamic meeting points created through the intergenerational cooperative inquiry, where relationships both shaped and were played out through physical and intra-subjective temporal experiences. How children and adults participated in the mini-conference and their final evaluations revealed not only a reversal of some of the initially negative views about participation but also that such participation is possible. The children were excited and motivated by the adults' visit, taking time to create an inviting and participatory environment, sharing drinks and snacks and chatting freely with them. The adults recognised 'The great involvement of the children' as they began to learn from each other. They identified benefits of such participation, for example: 'Helps to develop children/adult relationships' and joy at sharing their experiences:

'The interview - the reactions from the children when they heard about the differences. Especially when I said I had to walk 45 minutes to high school.'

This new emphasis within the theme understanding contrasted considerably with the questionnaire analysis where involvement, well-being, understanding and ownership all featured in less than $10 \%$ of the responses and those associated with equity and interactions accounted for the rest. Reduced emphasis was not because these no longer mattered to participants but reflected how they had adopted new, cooperative ways of interacting that led to increases in their understanding of each other's experiences and perspectives, drawing attention to and emphasis on this theme. The children really valued the intergenerational work resonating with Bessell (2017) and describing benefits such as: 'It helps you interact better, ' and 'Because we see both sides of the story.' 
This shaping of the participatory space in terms of both physical and intersubjective experience by the children and resultant shift in emphasis on certain themes about participation, was also important when considering the co-constructed intergenerational views about what schools should be for. The adults suggested their involvement helped everyone to think more deeply about education:

'Schooling has changed so much since I was at school and it's not all about education.'

Their cooperative inquiry also enabled all to recognise children's capacities to participate in co-constructing ideas and in doing so spend time really thinking about education in its broadest sense, and beyond their limited current experience. The main emphasis on themes about education was relationships; both children and adults described negative relationships in schools during the research and then in co-constructing their views they expressed how schools should encourage better ways of relating: 'To help you mix with all ages,' 'Help you make new friends,' 'To be part of a community' and to 'Be good to each other.' Their coconstructed drawings represented education as a means of human flourishing (Brighouse, 2007; Fielding and Moss, 2011); they wanted schools to ensure each child becomes a 'Good rounded person' who is 'Happy in life!' has 'Respect,' 'Tolerance' and 'Patience.' and 'Never quit.' They thought schools should give children 'LOVE' [participants' emphasis].

These co-produced perspectives about the purpose of schools were not simply a combined set of adult and child views (in which case we would expect one or other group to dominate and a collection of the views already expressed earlier in the process); instead they demonstrated thoughtful consideration of the place of education in children's lives and how what happens in schools (rather than the subjects taught) influences their flourishing (Brighouse, 2007).

\section{THE IMPORTANCE OF INTERGENERATIONAL RELATIONSHIPS}

\section{Wider Community Involvement in Schools}

Intergenerational spaces that enable children's participation and opportunities to work with adults to co-construct views, require time, creative engagement and attention to relationships. By recognising that both children and adults are important actors within school systems, that adults from the broader school community can be important catalysts for change, and by enabling the opportunity for their creative engagement through inquiry, this research demonstrated how it is possible for children and adults to work together to co-construct what they believe matters (Guldberg et al., 2017). These new approaches, enacted through complexity-informed PAR (Crook, forthcoming), can serve to both shape educational spaces and also to build intergenerational inquiry so that complex problems, such as participation and the purpose of schools might be addressed. Through these, greater cooperation, broader ways of looking at problems and eventually deeper understanding through growing awareness and intersubjectivity can be achieved.

Robinson (2014), acknowledging the scarcity of research in primary schools from children's perspectives, suggests the importance of relationships for school ethos underpinned by children's rights: listening to the whole school community, positioning of children and teachers, and empowering children to lead their own learning. Intergenerational relationships 
must be authentic, and consistent to realise such wide-reaching change (Mannion, 2016). The approaches showed that richer relationships can be encouraged and help overcome concerns about problematic behaviour. Intergenerational cooperative inquiry enabled trust and trustworthiness to develop by directing energy toward care and responsibility for each other (Johnson and Johnson, 2016; Woodhead and Faulkner, 2008).

The children and adults started from narrow understandings of what is meant by participation in schools. Associations with individual autonomy, developmentalism and 'voice' based models of participation (Lundy, 2007) fail to take full account of children's active, practical participation in settings such as their homes and communities (Horgan et al., 2017; Wyness, 2013); this disconnects rights to a view from others such as those to information, expression, play and, when considered in its broadest sense, education. Arguably, neoliberalism is served by this separation and perception of diminishing children's capacities to engage democratically, reinforced when ignored by researchers, so that children's rights become something requiring facilitation and dependence on adults, rather than inalienable. Capacities did take time to emerge; experiment and time to try things out was vital to encourage this for both children and adults.

Whilst there is existing evidence of the benefits of children's inquiry as a means of participation (such as Kellett, 2005) this has tended to focus on individual benefits, rather than co-inquiry and co-production where communities learn and act together for change, missing these important opportunities for intergenerational participation and learning (Bessell, 2017; Guldberg et al., 2017). The intergenerational approach encouraged discussion that may have contributed to the children's regulation of behaviour, demonstrating children's propensity to shape their behaviours to social norms, but also prioritising collective participation (Raby, 2014). Furthermore, this challenged the generational structuring usually promoted through schools, suggesting a need for further research about generational order and relationships (Punch, 2019). The approach triggered a cycle of experience and imaginings that enabled children to contemplate what they need to do, take action and evaluate progress, albeit with support from the teacher and in this case the researcher in a scaffolding role. It is unclear whether the school's Catholic ethos and context also informed the children's behaviours; however, it should be noted that a second study by the author in a non-faith school showed similar results. On-going participatory action, rather than one-off events, appears necessary to embed changes in intergenerational relationships.

The shifts in emphasis of views about children's participation that occurred, and the importance of an ongoing cycle, suggested a 'temporally situated view of agency' is necessary for understanding interactions between generations which are framed by past (iterative patterns of thought and action), present (practical and evaluative) and future (projective or imagined hopes, fears or desires) factors (Corsaro, 2005: 233). This situates participation processes in time and space, bound with intersubjective aspects of relationships and suggesting agency as relational and collective, rather than simply independent capability. This presents a challenge to patriarchal, production-based processes and agendas that currently define schooling and position children (Harris, 2005; Krstić, 2016) and a potential way forward by building on the rich resources already available: the children and adults who constitute broad school communities. Significantly, through children co-directing spaces for participation, shared understanding emerged enabling richer relationships, thus the cycle can continue. 


\section{Children's positioning}

Relationships and awareness of interconnectedness matter (Bessell, 2017; Haggis, 2008; Theobald and Kultti, 2012). Recent research shows a clear link between active participation, relationships of recognition, and well-being (Anderson et al., 2019; Graham et al., 2018; Mannion et al., 2015; Thomas et al., 2016). It matters to children that they are listened to (Robinson, 2014) and that they are recognised and understood (Thomas, 2012); the contrast between children's and adults' initial fears at the beginning of the study and their positive evaluation at the end tends to reinforce this. UNICEF's Rights Respecting School Award has been successful in generating better relationships in schools between teachers and children, and between peers, and respect for others locally and outside their communities (Sebba and Robinson, 2010); less evident is whether it changes children's positioning. The approach enabled children to gradually get to know adult volunteers on their terms: they decided how they would conduct inquiry, what they would ask, and how to include adults. Both individual agency and collective endeavour were revealed as important for children's participation, challenging dualisms (Theobald, 2019) by positioning them as capable researchers, rather than passive or waiting for adults to provide them with knowledge.

The teacher's recognition of the children's capabilities removed a latent barrier to their autonomy, so they used the school environment and resources necessary for inquiry. They responded to growing freedom by attending to their own behaviours, recognising the needs of others to develop an inclusive space, contesting other 'voice' based research that assumes children are happy for disruptive children to be removed from class (Robinson, 2014). They demonstrated how community members are rich resources for schools truly concerned with broader education (Fielding and Moss, 2011) by identifying shared experiences, and together trying to understand how schooling and children's lives had changed, valuing their knowledge and support.

\section{The Teacher's Role}

The teacher appeared to genuinely care that each child was included, was learning, and was supported by their group to do so; she hoped this would help during their transition to secondary school, something that Robinson (2014) suggests is also important to children. She was willing to try different approaches to achieve this, providing more than instrumental support by taking time to listen and talk with the children and help them identify ways forward. Theobald and Kultti (2012) suggests that teachers facilitate participation using a variety of groupings and talk, as well as committing time to processes involved This teacher moved beyond facilitator to scaffold the children's relationships and learning. Rather than making assumptions about children's capacities as motives for control (Punch, 2019), she considered them all trustworthy, able to make decisions and venture out of sight, with her role supporting and encouraging this. Unlike authoritarian, transmittive teaching, which requires constant classroom surveillance to micro-manage compliance, the teacher had time to stand back and reflect on what was working, acknowledge capabilities, and in doing so enabled the children to reshape the spaces of their learning through new positioning.

In order to fulfil the recommendation that the UNCRC should be the framework for education policies (Alexander 2010) and to ensure that every student is able 'to become an irreplaceable 
someone' (Osberg and Biesta, 2008: 326), the study's findings about educationalists explicit attention to the inequities implicit in generational order (Punch, 2009) may have wider implications for practice. The quality of trust and assumption of capability demonstrated by this teacher provided a necessary baseline for enabling children to shape school spaces and work together with their communities towards meaningful participation.

\section{CONCLUSION: RETHINKING EDUCATION THROUGH CHILDREN'S PARTICIPATION RIGHTS}

It is important to view educational spaces as intergenerational, dynamic meeting points of intra-subjective temporal experiences where relationships can and do change. Complexityinformed PAR (Crook, forthcoming) can open up opportunities for deeper intergenerational understanding about children's participation in schools because it establishes both children and adults as important actors, challenging assumptions about their positioning and roles. Cooperative intergenerational inquiry presents a suitable way for children and adults to work together to achieve this in school contexts, enabling them to creatively reflect and envisage change, whilst acknowledging the complex, networked nature of schools and all those involved. Whilst the views presented were those of only one school class of children and members of their community, these perspectives demonstrated the complexity of children's participation in such contexts and the need for more research informed by Childhood Studies that experiments in applying theory to practice in schools. Extending the approach to include community adults demonstrated what happened when the participants had chance to 're-see' other persons (Fielding and Moss, 2011:79). A strength of the intergenerational cooperative inquiry was the influence children had, not just on individual learning but in shaping educational spaces for change.

Human developments are always collective and shared with significant others (Corsaro, 2005). Without opportunities to develop rich relationships and participation, schools are undoing children's capacities to make the world a better place. The study demonstrated how children's participation can be encouraged and neoliberal pressures on children's education and participation (Bath et al., 2020; Brighouse, 2007; Fielding and Moss, 2011; Harris, 2005; Osberg and Biesta, 2008; Raby, 2014; Sahlberg, 2011) might be resisted through:

- Recognising classroom spaces as dynamic intra-subjective meeting points where relationships can grow, potentially enabling novelty and change through attention to intergenerational positioning.

- Recognising the importance of children's participation as an everyday experience in schools and children's capabilities to mobilise agency to shape and change classroom spaces.

- Facilitating intergenerational PAR through which children and adults can work together to identify, act upon and deepen understanding, about matters that affect children's education.

- Educationalists engaging with Childhood Studies and rights-based practice to potentially address calls for a broader, balanced, creative curriculum that considers children and communities engagement as integral (Alexander, 2010). 
The relevance of these strategies in other local and global contexts of schooling and educational policy development could usefully be explored through further experiments in complexity-informed PAR, through intergenerational projects and evaluations of these.

\section{ACKNOWLEDGEMENTS}

The author would like to thank Professor Nigel Patrick Thomas for his invaluable comments on earlier drafts of this paper.

\section{DATA AVAILABILITY STATEMENT}

The data that support the findings of this study are available on request from the corresponding author. The data are not publicly available due to privacy or ethical restrictions.

\section{REFERENCES}

Alderson P and Morrow V (2011) The ethics of research with children and young people: a practical handbook (2nd edition). London: Sage.

Alexander R (2010) Children, their world, their education: final report and recommendations of the Cambridge Primary Review. London: Routledge.

Anderson DL, Graham AP and Thomas NP (2019) Assessing student participation at school: developing a multidimensional scale. International Journal of Student Voice 5(1).

Crook DJ (forthcoming) A Case for Complexity-Informed Participatory Action Research with Young People.

Bath N, Daubney A, Mackrill D and Spruce G. (2020) The declining place of music education in schools in England. Children \& Society 00:1-15. https://doi.org/10.1111/ chso. 12386

Bessell S (2017) The role of intergenerational relationships in children's experiences of community. Children \& Society 31: 263-275.

Biesta G and Osberg D (2010) Complexity, education and politics from the inside-out and the outside-in: an introduction. In: Osberg D and Biesta G (eds) Complexity theory and the politics of education. Rotterdam: Sense Publishing.

Brighouse H (2007) On Education. London: Routledge.

Cilliers P (2005) Complexity, deconstruction and relativism. Theory, Culture \& Society 22(5): 255-267.

Corsaro WA (2005) Collective action and agency in young children's peer cultures. In: Qvortrup J (ed) Studies in modern childhood: society, agency, culture. Basingstoke: Palgrave MacMillan. 
Estyn (2019) https://www.estyn.gov.wales/thematic-reports/healthy-and-happy

Fielding M and Moss P (2011) Radical education and the common school. Abingdon: Routledge.

Freire P (1970) Pedagogy of the Oppressed. London: Penguin Group.

Gallagher M, Haywood SL, Jones MW and Milne S (2010) Negotiating informed consent with children in school-based research: a critical review. Children \& Society 24: 471-482.

Graham A, Truscott J, Simmons C, Anderson D and Thomas N. (2018) Exploring student participation across different arenas of school life. British Educational Research Journal 44(6): 1029-1046.

Guldberg K, Parsons S, Porayska-Pomsta K and Keay-Bright W (2017) Challenging the knowledge-transfer orthodoxy: knowledge co-construction in technology-enhanced learning for children with autism. British Education Research Journal 43(2): 394-413.

Haggis T (2008) 'Knowledge must be contextual': Some possible implications of complexity and dynamic systems theories for educational research. Educational Philosophy and Theory 40(1): 158-176.

Hall BL (2005) In from the cold? Reflections on participatory research from 1970-2005. Convergence XXXVIII (1): 5-24.

Harris N (2005) Empowerment and state education: rights of choice and participation. The Modern Law Review 68(6): 925-957.

Honneth A (1995) The Struggle for recognition: the moral grammar of social conflicts. Cambridge: Polity Press.

Horgan D, Forde C, Martin S and Parkes A (2017) Children's participation: moving from the performative to the social. Children's Geographies 15(3): 274-288, DOI: 10.1080/14733285.2016.1219022

Johnson DW and Johnson R (2016) Cooperative learning and teaching citizenship in democracies. International Journal of Educational Research 76: 162-177.

Kellett M (2005) Children as active researchers: a new research paradigm for the 21st century? NCRM Methods Review Papers NCRM/003. UK: ESRC National Centre for Research Methods. Available online at: http://eprints.ncrm.ac.uk/87/1/MethodsReviewPaperNCRM-003.pdf

Kindon S, Pain R and Kesby M (2007) Participatory action research: origins, approaches and methods. In: Kindon S, Pain R and Kesby M (eds) Participatory Action Research Approaches and Methods: Connecting People, Participation and Place. London: Routledge.

Kirschner PA, Sweller J and Clark RE (2006) Why minimal guidance during instruction does not work: an analysis of the failure of constructivist, discovery, problem-based, experiential, and inquiry-based teaching. Educational Psychologist 41(2): 75-86.

Krstić P (2016) Three naive questions: addressed to the modern educational optimism. Studies in Philosophy and Education 35:129-144. DOI 10.1007/s11217-015-9463-6 
Lawson N and Spours K (2011) Education for the Good Society: The values and principles of a new comprehensive vision, October 2011. London: Compass.

Lundy L (2007) 'Voice' is not enough: conceptualising Article 12 of the United Nations Convention on the Rights of the Child. British Educational Research Journal 33: 927-942. DOI:10.1080/01411920701657033

Mannion G (2016) Intergenerational education and learning: We are in a new place. In: Punch S, Vanderbeck R, Skelton T (eds.). Family, Intergenerationality and Peer-Group Relations. Geographies of Children and Young People, 5. London: Springer, pp. 1-21.

Mannion G, Sowerby M and L'Anson J (2015) How Young People's Participation in School Supports Achievement and Attainment. Scotland: Scotland's Commissioner for Children and Young People.

Miles MB, Huberman AM and Saldaña J (2013) Qualitative Data Analysis: A Methods Source Book, third edition. Sage Publications: Sage Publications Ltd.

Osberg D and Biesta G (2008) The emergent curriculum: navigating a complex course between unguided learning and planned enculturation. Journal of Curriculum Studies 40(3): 313-328.

Punch S (2019) Why have generational orderings been marginalised in the social sciences including childhood studies? Children's Geographies. DOI:0.1080/14733285.2019.1630716

Raby R (2014) Children's participation as neo-liberal governance? Discourse: Studies in the Cultural Politics of Education 35(1): 77-89. DOI: 10.1080/01596306.2012.739468

Robinson C (2014) Children, their voices and their experiences of school: what does the evidence tell us? York: Cambridge Primary Review Trust.

Rasmussen J (2010) Increasing complexity by reducing complexity: a Luhmannion approach to learning. In: Osberg D and Biesta G (eds) Complexity Theory and the Politics of Education. Rotterdam: Sense Publishing.

Sahlberg P (2011) The fourth way of Finland. Journal of Educational Change 12(2): 173185.

Sebba J and Robinson C (2010) Evaluation of UNICEF UK's Rights Respecting Schools Award. Final report, September 2010. London: UNICEF UK.

Smyth J (2014) Improving schools in poor areas: it's not about the organisation, structures and privatisation, stupid! Improving Schools 17(3): 231-240.

Theobald M (2019) UN Convention on the Rights of the Child: "Where are we at in recognising children's rights in early childhood, three decades on ...?”. International Journal of Early Childhood 51, 251-257.

Theobald M and Kultti A (2012) Investigating child participation in the everyday talk of a teacher and children in a preparatory year. Contemporary Issues in Early Childhood 13(3): 210-225. 
Thomas N (2012) Love, rights and solidarity: studying children's participation using Honneth's theory of recognition. Childhood 19(4): 453-466.

Thomas N, Graham A, Powell M and Fitzgerald R (2016) Conceptualisations of children's wellbeing at school: the contribution of recognition theory. Childhood 23(4): 506-520.

Woodhead M and Faulkner D (2008) Subjects, objects or participants? Dilemmas of psychological work with children. In: Christensen P and James A (eds) Research with Children: Perspectives and Practices. Taylor \& Francis Group.

Wyness M (2013) Global standards and deficit childhoods: The contested meaning of children's participation. Children's Geographies 11(3): 340-353. 